\title{
AUTO-EFICÁCIA, ATIVIDADES FÍSICAS E PRÉ-ESCOLARES
}

\author{
Tércio Alves Nascimento \\ Universidade Metodista de Piracicaba, Piracicaba, São Paulo, Brasil. \\ Rute Estanislava Tolocka \\ Universidade Metodista de Piracicaba, Piracicaba, São Paulo, Brasil.
}

\begin{abstract}
Resumo: Este estudo analisa auto-eficácia em situações de prática de atividade física em escolas infantis, observando-se 202 crianças entre dois e cinco anos de idade de 15 salas de aula. Trata-se de um estudo exploratório--descritivo, feito a partir de filmagens, verificando-se o aparecimento de traços de auto-eficácia, habilidades motoras, interações sociais e disposições pessoais. As atividades permitiram a manifestação de traços de auto-eficácia e estes estavam ligados aos recursos e disposições pessoais. As interações sociais favoreceram o aparecimento destes traços e isto pode ter ocorrido devido as experiências vicárias e a persuasão verbal. Conclui-se que estes traços de autoeficácia impulsionam a participação da criança na atividade ao mesmo tempo que são gerados por elas.

Palavras-chaves: Criança, Desenvolvimento Infantil, Educação Infantil
\end{abstract}

\section{Introdução}

Um crescente número de crianças tem sido atendido em escolas infantis e este número está aumentando rapidamente desde a promulgação da Lei de Diretrizes e Bases da Educação Nacional - LDB no. 9.394(BRASIL, 1996) e a meta do governo federal é que $50 \%$ das crianças de até três anos de idade esteja nas escolas até 2016 (BRASIL - MEC - 2011/ 2020).

Embora os Referências Curriculares Nacionais da Educação Infantil - RCN's (BRASIL, 1998) prevejam atividades físicas para promoção do desenvolvimento destas crianças, não existe a obrigatoriedade da Educação Física neste nível de ensino mas os profissionais que atuam com estas crianças oferecem atividades físicas tais como jogos e brincadeiras.

De outro lado é através do movimento que a criança se desenvolve em seus diferentes aspectos;por exemplo, Piaget (1990) relacionou- o com processos de formação e construção do pensamento; Winnicott (2000) ligou-o ao desenvolvimento emocional; vários estudos, dentre eles os de Lam et al (2010) e Costa et al (2011), mostram que o crescimento físico pode ser prejudicado com o sedentarismo.

Estudos têm mostrado que a participação em atividades físicas dentro deescolas infantis pode favorecer o desenvolvimento psico-social (De MARCO 2006; TOLOCKA, et. al., 2009; TOLOCKA; BROLO 2010; FARIA et. al. 2010; REVERDITO, 2011).

Considerando-se que nesta faixa etária muitas das experiências vividas ocorrerem através de atividades físicas, as mesmas podem estar ligadas a formação da auto-eficácia, que segundo Bandura (1986) é determinada pelo julgamento que as pessoas têm acerca de suas capacidades para alcançar determinados níveis de rendimento.Pode-se pensar a auto-eficácia como sendo a confiança de atuação diante de uma tarefa particular envolvida, por meio da 
qual a pessoa forma uma idéia subjetiva de sua habilidade para reagir às demandas ambientais.

Aauto-eficácia influencia no desempenho de uma atividade e, ao mesmo tempo, é influenciada por ela, tendo implicações no desenvolvimento da criança como um todo. Esta influência ocorre tanto por uma ação direta como pelo seu impacto nos processos de motivação, auto-regulação e auto-percepção, nas expectativas de resultados, bem como escolhas e interesses, que por sua vez, afetam o nível e o tipo de comportamento (BANDURA, 1981).

Quatro fatores contribuem para o desenvolvimento da auto-eficácia 1- as experiências vivenciadas pelo individuo, 2- as experiências vicárias ou as observações do outro, 3- a persuasão verbal e 4-percepção dos estados fisiológicos (BANDURA, 1997; SCHUNK; HANSON, 1989).

A auto-eficácia está relacionada a questão da aprendizagem (NEVES; FARIAS, 2007;RODRIGUES; BARRERA, 2007; OLIVEIRA; SOARES, 2011), mas pouco se sabe sobre a auto-eficácia em pré-escolares.

Assim este estudo tem como objetivo observar características ligadas a auto-eficácia que podem ser estimuladas em situações de prática de atividades físicas no ensino infantil.

\section{Metodologia}

Trata-se de um estudo exploratório-descritivo (VASCONCELOS, 2007). Foram observadas 202 crianças com idade entre dois e cinco anos, regularmente matriculadas em Instituições de Educação Infantil (IEIs) da Prefeitura de um Município no interior de São Paulo e 15 profissionais que atuam diretamente com elas nestas instituições. Tais profissionais foram selecionados aleatoriamente e vieram das cinco regiões da cidade.Tanto os profissionais que ministraram as atividades, quanto os responsáveis pelas crianças que delas participaram assinaram o Termo de Consentimento Livre e Esclarecido para a participação no estudo, que foi autorizado pela Secretaria de Educação do Município e aprovado pelo conselho de ética de uma universidade naquela cidade.

Materiais e métodos

Foi solicitado a cada profissional que realizassem atividades do dia a dia com as crianças durante 20 minutos e foram selecionados para este estudo apenas as atividades que relacionavam-se com a prática de atividades físicas. Tais atividades foram feitas dentro do ambiente natural da criança, na própria escola. Inicialmente, para familiarização das crianças com os pesquisadores e câmeras, as crianças foram filmadas brevemente e as imagens apresentadas a elas. Foi permitido o acesso das crianças às câmeras. Estas filmagens iniciais eram de aproximadamente 10 minutos e não foram consideradas para análise.

As imagens foram gravadas com duas filmadoras que se encontravam fixadas em um tripé, em diagonais opostas de um retângulo formado pela área onde a atividade foi realizadas, o espaço variou em decorrência do espaço utilizado pela profissional, uma vez que não há padrão para as classes nas diferentes escolas estudadas.

As imagens capturadas foram transferidas para um computador e analisadas utilizando o software Pinaclle Hollywood FX For Studio, que possibilita a visualização quadro a quadro em diferentes velocidades. 
Para a verificação de Traços de Auto-eficácia foi utilizado um Roteiro de Observação de Traços de Auto-eficácia (RTAE), elaborado para este fim,assumindo-se como base os quatro pilares referentes ao desenvolvimento da auto-eficácia segundo Bandura (1986).O Roteiro contém 10 itens, considerados como traços de auto-eficácia, que foram pontuados conforme sua ocorrência ou não, com exceção do item nove, com um ponto, se fossem observados. $\mathrm{O}$ item nove receberia esta pontuação caso não ocorressem.

Foram descritas as atividades realizadas bem como as disposições (curiosidade, iniciativa, liderança, participação, engajamento e empenho em atividades), demandas (potencial da criança de atrair ou rejeitar atenção e afeto) e relações inter-pessoais estabelecidas, e os recursos pessoais (correr, saltar, caminhar, engatinhar, equilibrar, lançar, arremessar, dentre outras) itens observados a partir de pressupostos da teoria Bioecológica do Meio Ambiente (BRONFENBRENNER, 1996; 2005).

Para a observação das inter-relações, foram considerado os momentos em que na busca de realizar a atividade proposta pelo professor os alunos se relacionaram reciprocamente com algum dos seus colegas de turmas ou com o próprio professor. Ou seja, se o aluno se expressou de alguma forma, se houve algum tipo de contato, se ocorreu alguma discussão na busca de solução de um problema e se houve algum trabalho em conjunto com o objetivo de realizar a tarefa proposta.

Para verificar relações sociais, por se tratar de um corte transversal no tempo foi utilizado um sociograma que é a representação gráfica das relações, ou seja é um diagrama que permite explorar graficamente a posição que ocupa cada individuo dentro do grupo, assim como todas as interações estabelecidas entre os diversos indivíduos (MORENO, 1992).

\section{Resultados}

Foram observados as atividades realizadas 15 classes totalizando e 202, onde 120 eram meninas e 82 eram meninos. Haviam crianças de 3, 4, 5 e 6 anos que compunham turmas do MI ao JII.

Cada classe realizou uma atividade. A atividade da classe 1de Roda cantada de Ciranda, atividade 2 de Brincar Livremente com brinquedos, atividade da classe 3 de Roda cantada Sentada, atividade da classe 4 de Estourar bolinhas de Sabão, atividade da classe 5 de Roda cantada com Gestos, atividade da classe 6 de Escorregar no Escorregado, atividade da classe 7 de acordar o amigo urso, atividade da classe 8 de circuito, atividade da classe 9 de história da serpente, atividade da classe 10 de acerta a figura, atividade da classe 11 de Barra Manteiga, atividade da classe 12 de Patinho feio, atividade da classe 13 de pegar a bola, atividade da classe 14 de Jogo de queimada e atividade da classe 15 de Dança da cadeira.

Foi observado nas atividades traços de auto-eficácia e referentes aos itens do RTAE (em anexo). $\mathrm{Na}$ atividade de Roda Cantada de Ciranda que as 12 crianças apresentaram traços de auto-eficácia, entre eles: de disposição, Persistência e de engajamento. E não apresentaram os traços de disputa, capacidade e insistência e confiança.

$\mathrm{Na}$ atividade de Brincar livremente com brinquedos, 7 crianças apresentaram traços de auto-eficácia: Engajamento, disposição e persistência os demais traços não foram verificados. Na atividade de Roda Cantada Sentado, 15 crianças apresentaram traços de autoeficácia traços os mais observados foram os de disposição, engajamento, e persistência, e os traços mais ausentes foram os de disputa e o de capacidade.

$\mathrm{Na}$ atividade de Estourar Bolinhas de Sabão, foi possível verificar que 21 crianças apresentaram traços de auto-eficácia sendo destacados mais os traços de disposição, disputa e 
engajamento e todas elas deixaram de apresentar algum traço, os menos freqüentes foram: capacidade insistência e confiança.

$\mathrm{Na}$ atividade de Roda cantada com Gestos, foi observado que 13 crianças apresentaram traços de auto-eficácia e 15deixaram de apresentar algum deles. Os traços mais observados foram o de persistência, disposição, e os mais ausentes foram capacidade, insistência, confiança e engajamento.

$\mathrm{Na}$ de Escorregar no Escorregador, foi constatado que as 10 crianças apresentaram traços de auto-eficácia, destacando de disposição, engajamento e persistência. E 10 crianças deixaram de apresentar traços, destacando-se a ausência de insistência e confiança.

$\mathrm{Na}$ atividade de Acordar o Amigo Urso, foi verificado que sete crianças apresentaram traços de auto-eficácia sendo que os mais frequientes foram o traço de disposição, engajamento. No entanto, foi constatado que as sete crianças também deixaram de apresentar traços de auto-eficácia sendo que os mais ausentes os foram os de disputa, capacidade insistência e confiança e superação.

$\mathrm{Na}$ atividade de Circuito, todas as 20 crianças apresentaram traços de auto-eficácia positivos os traços mais observados foram os de disposição persistência, insistência/confiança e engajamento, varias crianças não apresentaram os itens de disputa e capacidade.

$\mathrm{Na}$ atividade de História da serpente 20 crianças apresentaram traços de auto-eficácia, os traços mais ocorrentes foram os traços de engajamento, disposição e de persistência e estavam mais ausentes os de disputa e capacidade.

$\mathrm{Na}$ atividade de Apontar a Figura, foi constatado que cinco crianças apresentaram traços de auto-eficácia, destacando-se os traços mais ocorrentes como os de disposição, engajamento, iniciativa e persistência. 10 crianças não apresentaram algum traço, os que menos apareceram foram os de disputa, capacidade e superação.

$\mathrm{Na}$ atividade de Barra Manteiga, 13 crianças apresentaram traços de auto-eficácia; os traços de engajamento, e de persistência , foram os mais constatados. E os de insistência e confiança e superação o menos constatados.

$\mathrm{Na}$ atividade de Patinho feio, foi verificado que as 11 crianças apresentaram traços de auto-eficácia os mais ocorridos foram disposição, engajamento, iniciativa e de persistência e os que menos foram encontrados foram disputa, capacidade insistência e confiança e de superação.

$\mathrm{Na}$ atividade de Pegar a Bola, foi constatado que 15 crianças apresentaram traços de auto-eficácia traços sendo os mais observados disposição, disputa, engajamento e persistência. Os mais ausentes foram os de capacidade, insistência e confiança e superação.

$\mathrm{Na}$ atividade de Jogo de Queimada, foi observado as16 crianças apresentaram traços de auto-eficácia os traços que mais se destacaram foram os de disposição, engajamento , iniciativa e de persistência. e os mais ausentes foram o de capacidade, insistência e confiança, e de superação.

E na atividade de Dança das Cadeiras, foi constatado que 16 crianças apresentaram traços de auto-eficácia sendo que a maior ocorrência foram dos traços de disposição , disputa , persistência engajamento e de persistência entre os mais ausentes destacam-se os traços de capacidade e insistência e confiança . 


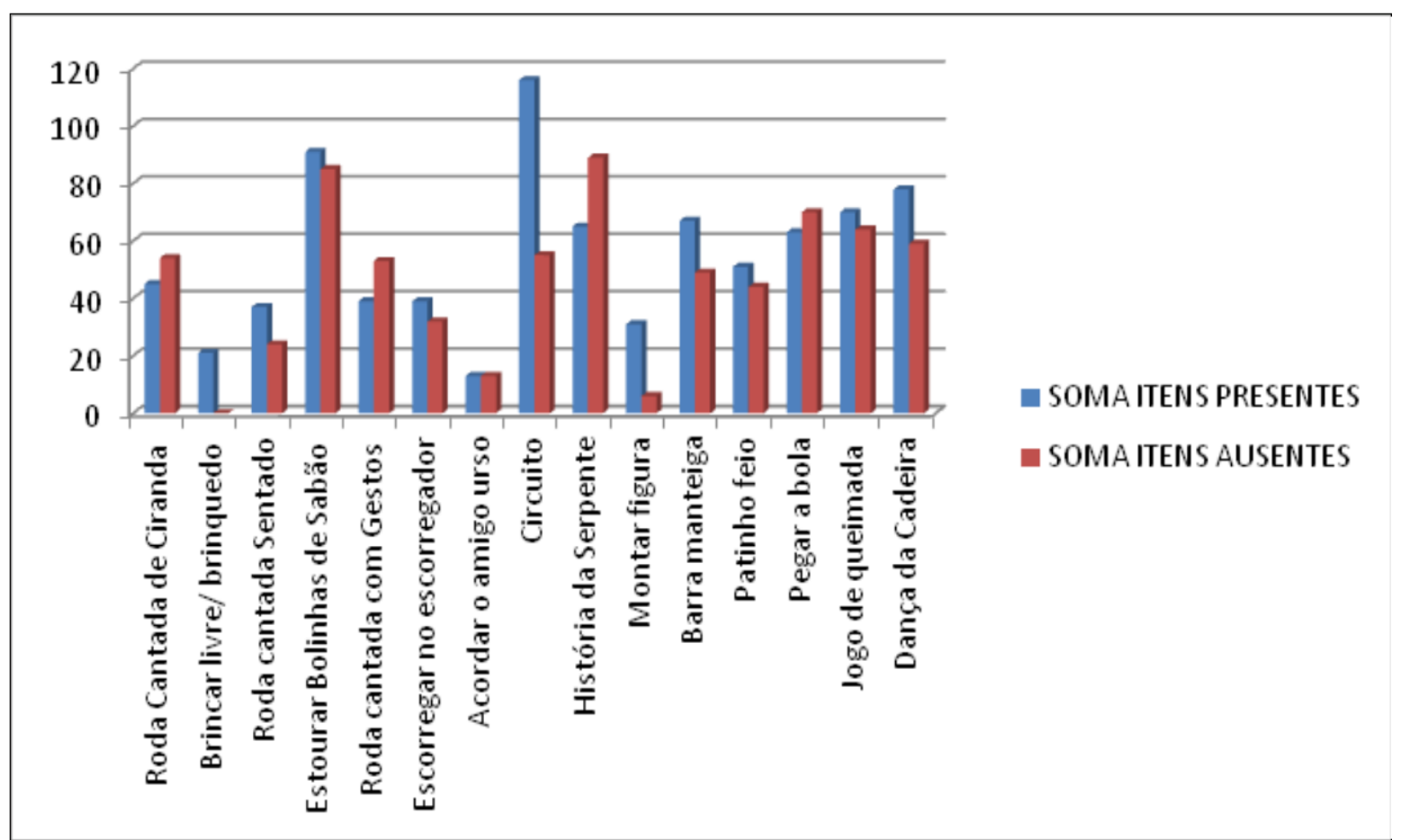

Figura 1. Gráfico de distribuição entre itens presentes e ausentes do RTAE

Das inter-relações observadas, foi contatado que na atividade $1 \mathrm{dez}$ crianças apresentaram inter-relações pessoais, na atividade 3 cinco crianças, na atividade 4 onze crianças, na atividade 6 sete, na atividade 7 três crianças, na atividade 8 doze crianças, na atividade 9 dezessete crianças, na atividade 10 cinco crianças, na atividade 11 treze crianças, na atividade 12 onze crianças, na atividade 13 sete crianças, na atividade 14 dezesseis crianças e na atividade 15 dez crianças.

Quadro 1, Número de inter-relação pessoais e atividades

\begin{tabular}{|c|c|c|c|c|c|c|c|c|c|c|c|c|c|c|c|}
\hline Atividade & 1 & 2 & 3 & 4 & 5 & 6 & 7 & 8 & 9 & 10 & 11 & 12 & 13 & 14 & 15 \\
\hline Alunos & 12 & 7 & 15 & 21 & 15 & 10 & 11 & 20 & 20 & 05 & 13 & 11 & 16 & 16 & 16 \\
\hline $\begin{array}{l}\text { Inter- } \\
\text { ções }\end{array}$ & rela- 10 & 0 & 5 & 11 & 0 & 7 & 3 & 12 & 17 & 5 & 13 & 11 & 7 & 16 & 10 \\
\hline
\end{tabular}

Foi verificado nas atividades crianças que apresentaram disposições geradoras 234 e disposições disruptivas 116 .

Quadro 2, Relação entre disposições geradoras e Disruptivas e as atividades. 


\begin{tabular}{llllllllllllllll}
\hline Atividades & 1 & 2 & 3 & 4 & 5 & 6 & 7 & 8 & 9 & 10 & 11 & 12 & 13 & 14 & 15 \\
\hline $\begin{array}{l}\text { Disposições } \\
\text { Geradoras } \\
\text { (crianças) }\end{array}$ & 11 & 7 & 13 & 20 & 10 & 7 & 3 & 20 & 20 & 5 & 10 & 9 & 10 & 11 & 7 \\
$\begin{array}{l}\text { Disposições } \\
\begin{array}{l}\text { Disruptivas } \\
\text { (crianças) }\end{array}\end{array}$ & 9 & 0 & 2 & 11 & 12 & 6 & 1 & 9 & 3 & 1 & 9 & 6 & 11 & 6 & 4 \\
\hline
\end{tabular}

Destas disposições tiveram também crianças que apresentaram ambos os tipos, geradoras e também disruptivas, sendo as disposições geradoras mais verificadas nas atividades as disposições de iniciativa e envolvimento e as disposições disruptivas que mais destacaram foram as de desatenção e falta de interesse.

Quadro 2. Relação entre atividades e disposições geradoras e disruptivas que mais destacaram

\begin{tabular}{llllllllllllllll}
\hline Atividades & 1 & 2 & 3 & 4 & 5 & 6 & 7 & 8 & 9 & 10 & 11 & 12 & 13 & 14 & 15 \\
\hline
\end{tabular}

\section{Disposições \\ Geradoras}

Iniciativa

Persistência 9

Envolvimento

$\begin{array}{llll}9 & 7 & 7 & 13\end{array}$

$7 \quad 3$

$\begin{array}{llll}19 & 20 & 5 & 9\end{array}$

9

Curiosidade

77

19

$\begin{array}{llll}10 & 9 & 10 & 10\end{array}$

\section{Disposições \\ disruptivas}

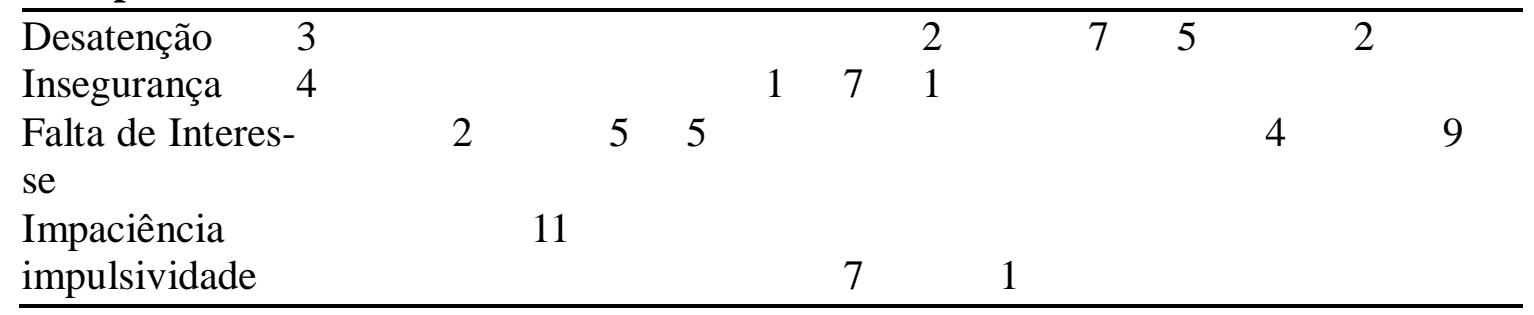

Dos recursos empregados pelas crianças nas atividades, e verificou-se o recurso de locomoção nas atividades de Roda cantada de Ciranda, Roda cantada sentado, Estourar bolinha de sabão, Escorregar no Escorregador, Acordar o Amigo Urso, Circuito, Roda da serpente, Barra e manteiga, Patinho Feio, Pegar a Bola, Jogo de Queimada e Dança da Cadeira. Os recursos de Manipulação foram verificados nas atividades de Estourar bolinhas de Sabão, Pegar a Bola e Jogo de queimada, e o os recursos de equilíbrio estático e Dinâmico foram observados nas atividades de roda cantada Sentado, Estourar bolinhas de sabão e de Circuito. 
Quadro 2, Relação Atividade Recurso pessoal.

\begin{tabular}{|c|c|c|c|c|c|c|c|c|c|c|c|c|c|c|c|}
\hline Atividades & 1 & 2 & 3 & 5 & 6 & 7 & 8 & 9 & 10 & 11 & 12 & 13 & 14 & 15 & Total \\
\hline Abaixar & 10 & & & & & & & & & & & & & & 10 \\
\hline Andar & 10 & 14 & 16 & & 7 & & & & & & & & 5 & 3 & 65 \\
\hline Arrastar & & & & & & & 13 & 7 & & & & & & & 20 \\
\hline Correr & & 14 & 15 & & 1 & 3 & 18 & & 1 & 13 & 11 & & 12 & 15 & 103 \\
\hline Deslizar & & & & & 7 & & & & & & & & & & 7 \\
\hline Engatinhar & & & & & & & 13 & 18 & 5 & & & & & & 36 \\
\hline Galopar & & & & & & & 1 & & & & & & & 1 & 2 \\
\hline Saltar H & 10 & & 15 & & & & 16 & & 4 & & & 6 & 9 & & 60 \\
\hline Saltar P & & & & & & & 4 & & 1 & & & & & & 5 \\
\hline Rolar & & & & & & & 19 & & & & & & & & 19 \\
\hline Lançar & & & & & & & & & & & & & 7 & & 7 \\
\hline Pegar & & & 15 & & & & & & & & & 5 & 6 & & 26 \\
\hline Equilibrar & & 14 & 15 & & & & 12 & & & & & & & & 41 \\
\hline D & & & & & & & & & & & & & & & \\
\hline Equilibrar E & & & & & & & 1 & & & & & & & & 1 \\
\hline Total & 30 & 42 & 76 & & 15 & 3 & 97 & 25 & 11 & 13 & 11 & 11 & 39 & 19 & \\
\hline
\end{tabular}

\section{Discussão}

Com relação aos traços de auto-eficácia, foi constatado segundo o RTAE o aparecimento de traços de auto-eficácia nas 15 atividade observadas neste estudo. Os traços mais ocorrentes foram os de disposição, engajamento, de disposição e o traço de persistência.

As atividades onde crianças mais apresentaram o traço de disposição foram as atividades de Circuito e de Barra manteiga . Nestas atividades as crianças demonstraram por repetidas vezes tentativas para realizar a atividade e a não se recusaram em participar. Com relação as atividades circuito e pode-se observar o desafio como uma característica da atividade que pode ter influenciado as crianças e na atividade de Barra manteiga e havia a disputa devido a brincadeira se caracterizar como brincadeiras de pega-pega

As atividades que mais apresentaram este traço engajamento foram as atividades Brincar livremente com brinquedos, Estourar bolinhas de sabão e de Barra manteiga. E as atividades que mais apresentaram o traço e Persistência foram as atividades de Brincar livremente com Brinquedos e Barra manteiga. Nestas atividades as crianças iniciaram a atividade e permaneceram até o final, todas a propostas quando ocorreram foram enfrentadas pelas crianças sem recusa.

Tais resultados concordam com Bandura (1997) onde ele aponta q a auto-eficácia está diretamente ligada à motivação, persistência e esforço de enfrentar desafios e obstáculos antes, durante e depois à realização da tarefa. E Cruz e Viana (1996) que com base em crenças 
de eficácia pessoal é que os indivíduos escolhem os desafios que vão tentar realizar, decidem a quantidade de esforço que vão despender, durante quanto tempo vão manter-se e serão persistentes em relação aos obstáculos e dificuldades apresentados.

Referentes às atividades que demonstraram menos traços de auto-eficácia foram constatadas as atividades de Acordar o amigo Urso, e de Brincar livremente com Brinquedos. Fatores que podem ter promovido estes resultados são a monotonia na atividade de acordar o amigo Urso, falta de desafio na atividade de Brincar livremente com Brinquedos, diferente do ocorrido nas atividades que mais apresentaram traços de auto-eficácia a atividade de Circuito e de Estourar Bolinhas de sabão.

Com relação traços de auto-eficácia e as inter-relações sociais, as atividades que mais oportunizaram estas ocorrências foram as de Acordar o amigo urso, Barra manteiga , Patinho feio e jogo de queimada.

Tais resultados podem ser originados em conseqüência das experiências vicárias e a persuasão verbal (BANDURA, 1997). No caso das experiências vicárias atuando na formação das crenças através de modelos sociais que providenciam informações, e que quanto maior a similaridade entre modelo e observador, maior a influência. E a persuasão verbal permite, que em situações adversas, uma influência na mobilização do esforço e na persistência para a realização de determinada tarefa (BANDURA, 1977, 1986, 1997). Estes resultados apontam também para a relação entre o sugerido por Bandura (1997) de que a persuasão verbal e as experiências vicárias promovem um melhor julgamento de eficiência do individuo sobre si mesmo, contribuindo com o desenvolvimento da auto-eficácia.

Referente a relação entre traços de auto-eficácia e recursos pessoais destacaram se as atividades de Acordar o amigo urso, Circuito , Acertar a figura, Barra e manteiga,de Patinho feio e Jogo de queimada, apresentando os traços de disposição, engajamento e persistência, e de insistência e confiança. Os recursos mais observados foram os de locomoção de correr, andar, engatinhar, saltar e de manipulação de pegar e arremessar. Tais resultados podem ter sido demonstrados devido às experiências de êxitos vivenciadas por estas crianças. Estas experiências podem ter corroborado com o desenvolvimento de recursos pessoais. Com isto, a realização destas atividades podem ser frutos de experiência de êxitos das crianças permitindo a elas interagir com o meio ambiente,vivenciando novos desafios, que as fará desenvolver-se.

Referente aos traços de auto-eficácia e disposições geradoras as atividades que mais oportunizaram esta ocorrência foram as atividades de Brincar livremente com brinquedos, Acordar o amigo urso e de Circuito, destacando os traços de auto-eficácia de engajamento e persistência em ambas as atividades, e também o de disposição nas atividades de Acordar o amigo urso de Circuito destacando as disposições geradoras de de engajamento, iniciativa, persistência e curiosidade. Esta relação entre os traços de auto-eficácia e disposições geradoras podem ser reflexo dos desafios que ocorreram nas atividades,permitindo que as crianças tivessem disposição (traço de auto-eficácia), para iniciar a atividade, onde podemos inferir que as percepção de auto-eficácia das crianças promoverão disposição nelas para envolver-se com a atividade.

Desta forma ao observar a auto-eficácia como elemento que pode estimular a curiosidade, a iniciativa, o envolvimento na atividade, a persistência, a impulsividade, a exclusividade, a impaciência ou a falta de interesse, a indiferença e a insegurança, e os recursos locomotores, manipulativos e de equilíbrio, indica que estas categorias relacionam-se com as disposições que a criança apresenta para realizar uma atividade.

Assim o uso de jogos e brincadeiras que exigem uso de habilidades motoras favorece não só o desenvolvimento de habilidades (recursos pessoais) mas de disposições geradoras que podem 
estar podem estar ligados ao aparecimento da auto-eficácia. Bandura (1986) afirma que o desenvolvimento da auto-eficácia advém também das experiências que são vividas pelo individuo. Entendendo que a auto-eficácia é um sentimento que o individuo tem de que é capaz de realizar determinada tarefa (BANDURA, 1986), possuir recursos pessoais para realizar a tarefa torna-se um fator importante para se ter auto-eficacia e envolver-se na atividade, manifestando disposições que podem ser geradoras ou disruptivas.

Tais disposições podem estar relacionadas com as experiências de êxitos apresentado por (BANDURA 1997) como a fonte mais importante para formações das crenças de autoeficácia no individuo. Bzuneck (2001) diz que os êxitos continuados das tarefas similares proporcionam informação ao aluno de que poderá dar conta de uma nova tarefa, ou viceversa. Sendo que estes êxitos que podem estar atrelados ao conjunto de recursos que o individuo possui para realizar determinada tarefas.

Copetti (2001) observando a pratica esportiva na modalidade de tênis realizado por crianças verificou um conjunto de disposições, constatadas na vontade das crianças e adolescente em iniciarem-se no esporte e permanecer engajados na modalidade; para ele estas evidências apontaram também para a disposição de conceituar o desempenho, quando positivo e negativo, ou seja, para abandonar ou permanecer na atividade e para a autoeficácia, estabelecendo uma relação que a auto-eficácia tem com as disposições da pessoa.

Bandura (1986) considera que os julgamentos de auto-eficácia são uma espécie de mediadores entre as reais capacidades (aptidões, conhecimentos e habilidades) e o próprio desempenho, ou seja, não significa que julgar-se eficiente, torna o individuo de fato capaz e habilidoso e engajado para realizar uma determinada atividade com sucesso. Quando a criança possui o recurso ou habilidade para realizar uma determinada tarefa, este fator por fazê-la julgar-se auto-eficiente e com disposição de envolver-se na tarefa.

Bandura (1997) sugere que a auto-eficácia está diretamente ligada à motivação, persistência e esforço de enfrentar desafios e obstáculos antes, durante e depois à realização da tarefa. Bronfenbrenner; Morris (2006) apresentam a disposição como as forças psicológicas necessária para desencadear uma ação, sendo essa força resultante da interação pessoa/contexto, chamada de motivação. Ou seja, para que a criança engaje em uma atividade ela precisaria julgar-se auto-eficiente em realizá-la.

Desta forma é possível haver uma manifestação da disposição geradora como conseqüência da auto-eficácia que a criança apresentou, além disto, o sentimento de auto eficiência da criança pode ser sustentado pelos recursos que ela possui, advindos das experiências vividas em situações semelhantes.

Desta forma,os atributos da pessoa mencionados por Bronfenbrenner na Teoria Bioecológica do Desenvolvimento Humano (1992) podem ser entendidos aqui, como elementos que geram e são gerados a partir do senso de auto-eficácia que o individuo possui, o que torna esse processo de interação do individuo com o meio ambiente um procedimento contribuinte também para o desenvolvimento da auto-eficácia, dando a este constructo psicológico um status de recurso pessoal.

\section{Considerações Finais}

Foi possível verificar através deste estudo que as atividades permitiram surgimento de inter-relações pessoais, as crianças puderam envolver-se umas com as outras através de toques, conversas e em alguns momentos discussões e empurrões. 
As atividades proporcionaram também a manifestação de recursos pessoais de a) locomoção: andar, arrastar, correr, deslizar, engatinhar, galopar e saltar; b) manipulação: arremessar, chutar, pegar-receber e rolar; c) equilíbrio estático e equilíbrio dinâmico.

As atividades proporcionaram manifestação de disposições geradoras e como de curiosidade, engajamento, iniciativa, persistência, envolvimento e autonomia, e disruptivas como de desatenção, timidez, apatia, insegurança falta de Interesse, impulsividade, irresponsabilidade, insegurança, impaciência, indiferença, distração e comportamento explosivo.

Foi constatado também que as atividades permitiram a manifestação de traços de autoeficácia de disposição, disputa, capacidade, persistência, insistência e confiança, engajamento e superação. E As atividades observadas demonstraram também uma relação entre traços de auto-eficácia e recursos pessoais. Sendo que esta ligação pode ser resultado do julgamento de eficiência que a criança fez quando ela se deparou com a atividade e entendendo que ela era capaz de realiza-la devido as habilidades que possuía.

Outra relação encontrada foi entre traços de auto-eficácia e disposições geradoras. Estes resultados podem ter ocorrido devido ao sentimento de auto-eficácia apresentado pela criança para realizar a tarefa. Foi observado que as atividades promoveram ainda relação entre auto-eficácia e inter-relações pessoais, sendo que esta relação pode ter sido estabelecida devido as experiências vicárias e a persuasão verbal, que ocorreram no momento em as crianças estavam realizando a atividade, apontando desta maneira que as inter-relações pessoais podem promover o desenvolvimento da auto-eficácia.

Desta forma pode-se inferir que a auto-eficácia é um elemento que advêm das relações estabelecidas com o meio ambiente e que ela influencia nas relação que serão formadas e é influenciada por elas também, atuando diretamente no processo de desenvolvimento da criança.

\section{SELF-EFFICACY, PHYSICAL ACTIVITIES AND PRESCHOOL}

Abstract: This study analyzes self-efficacy in situations of physical activity in children's schools, observing 202 children between two and five years of age of 15 classrooms. This is a descriptiveexploratory study, made from footage, with the appearance of traces of self-efficacy, motor skills, social interaction and personal arrangements. The activities enabled the demonstration of efficacy and these were linked to resources and personal arrangements. The social interactions the appearance of these favored traits and this may have occurred because the experiences vicárias and verbal persuasion. It is concluded that these traces of self-efficacy are promoting the child's participation in the activity at the same time that are generated by them.

Key-words: Child, Child development, Child Rearing

\section{AUTOEFICACIA, ACTIVIDADES FÍSICAS Y PREESCOLAR}

Resumen: Este estudio analiza la autoeficacia en situaciones de actividad física en las escuelas infantiles, 202 niños entre dos y cinco años de edad de 15 salones de observación. Este es un estudio descriptivo y exploratorio, hecho de material de archivo, con la aparición de rastros de autoeficacia, motor habilidades, interacción social y acuerdos personales. Las actividades permitió la demostración de la eficacia y éstos estaban vinculados a los recursos y los arreglos personales. Las interacciones sociales favorecido de la aparición de estos rasgos y esto puede haber ocurrido porque las experiencias vicárias y persuasión verbal. Se concluye que estos rastros de autoeficacia están promoviendo la participación del niño en la actividad al mismo tiempo que se generan por ellos. 
Palabras clave: Niño, Desarrollo infantil, Crianza del Niño.

\section{Referências}

BANDURA, A. Self-efficacy: Toward a unifying theory of behavioral change. Psychological Review, v.84, p.191-215,1977.

BANDURA, A .Social learning theory. Englewood Clifs: Prentice-Hall, 1977.

BANDURA, A. Self-referent thought: A developmental analysis of self-efficacy. In: Flavell J. H; Ross, L. (Orgs.), Social and cognitive development: Frontiers and possible futures,pp. 200-239. Cambridge: Cambridge University Press. 1981.

BANDURA, A. Social fundations of thought and action: a social cognitive theory. Englewood Clifs: Prentice-Hall, 1986.

BANDURA, A. Self-efficacy: The exercise of control. New York: W.H. Freeman. 1997.

BRASIL. Lei de Diretrizes e Bases da Educação Nacional. Lei no 9.394/96, de 20 de dezembro de 1996. Disponível em: http://www.planalto.gov.br/ccivil_03/leis/19394.htm. Acesso em: 31 jul 2013.

Ministério da Educação e da Cultura. Secretaria de Educação Básica. Referencial curricular nacional para a educação infantil. 1998. Brasília. v.1. Disponível em: http://portal.mec.gov.br/seb/arquivos/pdf/rcnei_vol1.pdf. Acesso em: 31 jul 2013.

.Plano Nacional de Educação: Metas e Estratégias2011/2020. Disponível em :http://fne.mec.gov.br/images/pdf/notas_tecnicas_pne_2011_2020.pdf. Acesso em:31 jul 2013.

BROLO, A. L. R. Desenvolvimento infantil e vivências lúdicas sob a ótica da Teoria Bioecológica. 2008. 126f. Dissertação (Mestrado em Educação Física) - Faculdade de Ciências da Saúde, Programa de Pós-graduação em Educação Física, Universidade Metodista de Piracicaba, Piracicaba.

BRONFENBRENNER, U. Ecological Systems theory.In VASTA, ROSS.Six theories of child development: revised formulations and current issues. London: Jessica KingleyPublischer, 1992.

BRONFENBRENNER, U. A ecologia do desenvolvimento humano: experimentos naturais e planejados. Porto Alegre: ArtesMédicas, 1996.

BRONFENBRENNER, U.; MORRIS, P. A.TheBioecological Model of Human Development. In: LERNER, R. M. Theoretical Models of Human Development.Handbook of Child Psychology.6 ed., NewYork: John WileyHoboken, 2006. 
BZUNECK, J. A. As Crenças de Auto-eficácia e o Seu Papel na Motivação do Aluno. In J. A. Bzuneck\& E. Boruchovitch (Orgs.), A motivação do aluno: contribuições da Psicologia contemporânea,p. 116-133. Petrópolis: Vozes. 2001.

COPETTI, F. Atributos pessoais de crianças que se engajam na prática esportiva: um olhar orientado pelo modelo Bioecológico. In: KREBS, R.J. et al. Os processos desenvolvimentais na infância. Belém: GTR Gráfica e Editora, 2003.

COSTA, M.B., SILVA, J.H.A., SIMÕES, A.C.S.R., ALVES, M.J.M. Obesidade infantil: características em uma população atendida pelo programa de saúde da família. Revista APS. v.14, n.3, p.283-288, 2011.

DEMARCO, M. C. Manifestações emocionais em atividades motoras de crianças de 5 a 6 anos de idade da educação infantil.2006. F.Dissertação (Mestrado em Educação Física) Faculdade de Ciências da Saúde, Programa de Pós-graduação em Educação Física, Universidade Metodista de Piracicaba, Piracicaba.

FARIA, M.C.M. et. al. Atividades motoras cotidianas e suas influências no desenvolvimento de pré-escolares. Rev. Movimento. v. 16, n. 01, p. 113-130, 2010.

LAM, J.W.K., et al. Physical activity and sedentary behaviours in Hong Kong primary school children: Prevalence and gender differences. Preventive Medicine. v. 51, p. 96-97, 2010.

MORENO, R. M.; RUBUSTINI, F. MACHADO, A. A. A auto-eficácia no Tênis de Campo: Uma Perspectiva da Psicologia do Esporte. Efdportes.com Revista Digital. Buenos Aires,Año 10, n. 93, 2006. Disponível em http://www.efdeportes.com,acessado em 03 setembro 2012.

OLIVEIRA, M. B.; SOARES, A. B.Auto-Eficácia, Raciocínio Verbal e Desempenho Escolar em Estudantes. Psicologia: Teoria e Pesquisa. v. 27, n. 1, p. 33-39, 2011.

PIAGET, J.A formação do símbolo na criança: imitação, jogo e sonho, imagem e representação. Rio de Janeiro: Livros Técnicos e Científicos, 1990.

REVERDITO, R. S. Jogo e desenvolvimento: Estudo com crianças de 05 e 06 anos em uma escola privada na cidade de Hortolândia/S.P. 2011.214f. Dissertação (Mestrado em Educação Física) - Faculdade de Ciências e Saúde, Programa de Pós-graduação em Educação Física, Universidade Metodista de Piracicaba, 2011.

TOLOCKA, R. E.; BROLLO, A. L. Atividades Físicas em instituições de ensino infantil: uma abordagem Bioecológica. Rev. Bras. Cineantropom. Desempenho Hum, v.12, n. 2, p. 140$147,2010$.

TOLOCKA, R. E. et. al. Como brincar pode auxiliar no desenvolvimento de crianças préescolares. Liceri. v. 12, n. 1, 2009. 
Recebido em: 31/07/2013

Revisado em: 21/07/2014

Aprovado em: 01/12/2014

Endereço para correspondência:

tercio.nascimento@unasp.edu.br

Tércio Alves Nascimento

Universidade Metodista de Piracicaba, Faculdade de Ciências da Saúde, Educação Fisica.

Campus Taquaral - Rodovia do Açucar KM 156

13400-911 - Piracicaba, SP - Brasil 